\title{
Consensus statement on the transition process from pediatric care to adult care in patients with chronic inflammatory rheumatic diseases with childhood-onset
}

\author{
Inmaculada Calvo ${ }^{1 *}$, Jordi Anton², Sagrario Bustabad ${ }^{3}$, Marisol Camacho ${ }^{4}$, Jaime De Inocencio ${ }^{5}, M^{a}$ Luz Gamir ${ }^{6}$, \\ Genaro Graña ${ }^{7}$, Lucía La Cruz ${ }^{8}$, Juan Carlos López-Robledillo ${ }^{9}$, Marta Medrano ${ }^{10}$, Rosa Merino ${ }^{11}$, \\ Consuelo Modesto ${ }^{12}$, Esmeralda Nuñez ${ }^{13}$, Ma Jesus Rua $^{14}$, Vicent Torrente ${ }^{15}$, Carmen Vargas ${ }^{16}$, Estibaliz Loza ${ }^{17}$, \\ NextStep working group
}

From 21st European Pediatric Rheumatology (PReS) Congress

Belgrade, Serbia. 17-21 September 2014

\section{Introduction}

Many young people with childhood-onset diseases, including rheumatic diseases, continue to require medical care into adult life. Although there is an extensive evidence base for the need of transitional care, there is a paucity of robust outcome data and a great variability on the models of transitional care.

\section{Objectives}

To develop recommendations on the transition from pediatric care to adult care in patients with chronic inflammatory rheumatic diseases with childhood-onset based on the best evidence and experience.

\section{Methods}

Recommendations were generated following nominal group methodology and Delphi technique. A panel of experts was established (8 pediatricians, 8 rheumatologists). A systematic literature review (on transitional care) and a narrative review (websites, clinical guidelines and other relevant documentation) were performed and presented to the panel in the $1^{\text {st }}$ panel meeting to be discussed and to help define recommendations. A first draft of recommendations was generated and circulated for comments and wording refinements. Focal groups with adolescents, young adults and parents were separately. In a $2^{\text {nd }}$ panel meeting the focus group results along with

${ }^{1}$ Hospital La Fe, Valencia, Spain

Full list of author information is available at the end of the article the input from invited nurses and psychologists were used to established definitive recommendations. Then, a Delphi process (2 rounds) was carried out. A large group of 70 pediatricians and rheumatologists took part. Recommendations were voted from 1 (total disagreement) to 10 (total agreement). We defined agreement if at least $70 \%$ voted $\geq 7$. The level of evidence and grade or recommendation was assessed using the Oxford Centre for Evidence-based Medicine Levels of Evidence.

\section{Results}

Transition care was defined as a purposeful, planned process that addresses the medical, psychosocial and educational/vocational needs of adolescents and young adults with chronic inflammatory rheumatic diseases with childhood-onset as they move from child-centred to adultoriented health care systems. The consensus covers: transition needs, barriers and facilitators, transitional issues (objectives, participants, content, phases, timing, plans, documentation, and responsibilities), physicians and other health professionals knowledge and skills requirements, models/programs, strategies and guideline for implementation. A total of 19 recommendations were developed.

\section{Conclusion}

These recommendations are intended to provide pediatricians, rheumatologists, patients, families and other stakeholders with a consensus on the transition process 
from pediatric care to adult care in patients with chronic inflammatory rheumatic diseases with childhood-onset.

\section{Disclosure of interest}

I. Calvo: None declared., J. Anton: None declared., S. Bustabad: None declared., M. Camacho: None declared., J. De Inocencio: None declared., M. L. Gamir: None declared., G. Graña: None declared., L. La Cruz: None declared., J. C. López-Robledillo: None declared., M. Medrano: None declared., R. Merino: None declared., C. Modesto: None declared., E. Nuñez: None declared., M. J. Rua: None declared., V. Torrente: None declared., C. Vargas: None declared., E. Loza Grant / Research Support from: Abbvie.

\section{Authors' details}

${ }^{1}$ Hospital La Fe, Valencia, Spain. ${ }^{2}$ Hospital Sant Joan de Deu, Esplugues de Llobregat, Spain. ${ }^{3}$ Hospital Universitario de Canarias, Santa Cruz de Tenerife, Spain. ${ }^{4}$ Hospital Universitario Virgen del Rocío, Sevilla, Spain. ${ }^{5}$ Hospital 12 de Octubre, Madrid, Spain. ${ }^{6}$ Hospital Ramón y Cajal, Madrid, Spain. ${ }^{7}$ Complejo Hospitalario Universitario A Coruña, La Coruña, Spain. ${ }^{8}$ Hospital Universitari Son Dureta, Mallorca, Spain. ${ }^{9}$ Hospital del Niño Jesús, Madrid, Spain.

${ }^{10}$ Hospital Universitario Miguel Servet, Zaragoza, Spain. ${ }^{11}$ Hospital La Paz, Madrid, Spain. ${ }^{12}$ Hospital Vall d'Hebron, Barcelona, Spain. ${ }^{13}$ Hospital Regional Universitario Carlos Haya, Malaga, Spain. ${ }^{14}$ Hospital Universitario Cruces, Barakaldo, Spain. ${ }^{15}$ Hospital Sant Joan de Déu, Espluques de Llobregat, Spain. ${ }^{16}$ Hospital Universitario Virgen de la Macarena, Sevilla, Spain.

${ }^{17}$ Institute for Musculoskeletal health, Madrid, Spain.

Published: 17 September 2014

doi:10.1186/1546-0096-12-S1-P85

Cite this article as: Calvo et al:: Consensus statement on the transition process from pediatric care to adult care in patients with chronic inflammatory rheumatic diseases with childhood-onset. Pediatric

Rheumatology 2014 12(Suppl 1):P85.

\section{Submit your next manuscript to BioMed Central} and take full advantage of:

- Convenient online submission

- Thorough peer review

- No space constraints or color figure charges

- Immediate publication on acceptance

- Inclusion in PubMed, CAS, Scopus and Google Scholar

- Research which is freely available for redistribution

Submit your manuscript at www.biomedcentral.com/submit 